\title{
[3]Pseudorotaxane-Like Complexes Formed between Bipyridinium Dications and Bis-p-xylyl[26]crown-6
}

\author{
Pin-Nan Cheng, ${ }^{\dagger}$ Chi-Feng Lin, ${ }^{\dagger}$ Yi-Huang Liu,${ }^{\dagger}$ Chien-Chen Lai, ${ }^{\ddagger}$ \\ Shie-Ming Peng, ${ }^{\dagger}$ and Sheng-Hsien Chiu ${ }^{*}, \dagger$
}

\begin{abstract}
Department of Chemistry, National Taiwan University, No. 1, Sec. 4, Roosevelt Road, Taipei, Taiwan 10617, R.O.C., and Department of Medical Genetics and Medical Research, China Medical University Hospital, Taichung, Taiwan, R.O.C.
\end{abstract}

shchiu@ntu.edu.tw

Received November 4, 2005
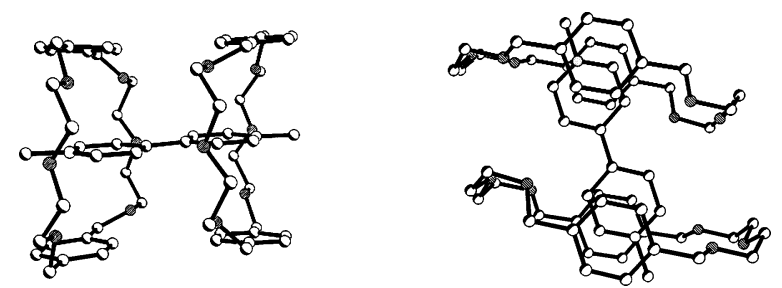

The crown ether BPX26C6 forms a [3]pseudorotaxane-like complex with the $N, N$-dimethyl-4,4'-bipyridinium dication both in solution and in the solid state. The facile one-pot synthesis of a [2]rotaxane from neutral precursors-BPX26C6, 4,4'-dipyridyl, and 3,5-di-tert-butylbenzyl bromide-suggests that BPX26C6 may bind to (mono)pyridinium cations in a [2]pseudorotaxane-like manner.

The synthesis of functional interlocked molecules continues to attract much attention because these machine-like molecules ${ }^{1}$ have been demonstrated to have potential applicability in mesoscale molecular electronic devices. ${ }^{2}$ Many functional supramolecular systems take advantage of the structural simplicity and redox activity of alkyl pyridinium salts; for example, $N, N^{\prime}$-dialkyl-4,4'-bipyridinium dications are often studied as guest moieties for synthetic host molecules, such as cucurbiturils, ${ }^{3}$ cyclophanes, ${ }^{4}$ calixarenes,${ }^{5}$ cryptands,${ }^{6}$ and crown ethers. ${ }^{7}$ Many synthetic interlocked molecules, such as rotaxanes, ${ }^{8}$ comprise bipyridinium ion and crown ether

\footnotetext{
National Taiwan University.

China Medical University Hospital.

(1) (a) Collin, J.-P.; Dietrich-Buchecker, C.; Gaviña, P.; Jiménez-Molero M. C.; Sauvage, J.-P. Acc. Chem. Res. 2001, 34, 477. (b) Leigh, D. A.; Wong, J. K. Y.; Dehez, F.; Zerbetto, F. Nature 2003, 424, 174. (c) Badjić, J. D.; Balzani, V.; Credi, A.; Silvi, S.; Stoddart, J. F. Science 2004, 303, 1845.

(2) (a) Molecular Electronics: Science and Technology; Aviram, A., Ratner, M., Eds.; New York Academy of Sciences: New York, 1998. (b) Collier, C. P.; Mattersteig, G.; Wong, E. W.; Luo, Y.; Beverly, K.; Sampaio, J.; Raymo, F. M.; Stoddart, J. F.; Heath, J. R. Science 2000, 289, 1172. (c) Yu, H.; Luo, Y.; Beverly, K.; Stoddart, J. F.; Tseng, H.-R.; Health, J. R. Angew. Chem., Int. Ed. 2003, 42, 5706.
}

[e.g., bis-p-phenylene[34]crown-10 (BPP34C10)] components. ${ }^{9}$ In these syntheses, the bipyridinium dication units have generally been preinstalled within the guest component as recognition sites for crown ethers prior to the formation of the final interlocked rotaxanes, but the requirement for

(3) (a) Kim, H.-J.; Jeon, W. S.; Ko, Y. H.; Kim, K. Proc. Natl. Acad. Sci. U.S.A. 2002, 99, 10. (b) Ong, W.; Kaifer, A. E. J. Org. Chem. 2004, $69,1383$.

(4) Lukyanenk, N. G.; Kirichenko, T. I.; Lyapunov, A. Y.; Mazepa, A. V.; Simonov, Y. A.; Fonari, M. S.; Botoshansky, M. M. Chem. Eur. J. 2005, 11, 262.

(5) (a) Schalley, C. A.; Castellano, R. K.; Brody, M. S.; Rudkevich, D. M.; Siuzdak, G.; Rebek, J., Jr. J. Am. Chem. Soc. 1999, 121, 4568. (b) Araki, K.; Watanabe, T.; Oda, M.; Hayashida, H.; Yasutakeb, M.; Shinmyozub, T. Tetrahedron Lett. 2001, 42, 7465.

(6) (a) Huang, F.; Fronczek, F. R.; Gibson, H. W. J. Am. Chem. Soc. 2003, 125, 9272. (b) Huang, F.; Switek, K. A.; Zakharov, L. N.; Fronczek, F. R.; Slebodnick, C.; Lam, M.; Golen, J. A.; Bryant, W. S.; Mason, P. E.; Rheingold, A. L.; Ashraf-Khorassani, M.; Gibson, H. W. J. Org. Chem. 2005, 70, 3231 .

(7) (a) Allwood, B. L.; Shahriari-Zavareh, H.; Stoddart, J. F.; Williams, D. J. J. Chem. Soc., Chem. Commun. 1987, 1058. (b) Allwood, B. L.; Spencer, N.; Shahriari-Zavareh, H.; Stoddart, J. F.; Williams, D. J. J. Chem. Soc., Chem. Commun. 1987, 1064. (c) Huang, F.; Zakharov, L. N.; Rheingold, A. L.; Ashraf-Khorassani, M.; Gibson, H. W. J. Org. Chem. 2005, 70, 809 . 
bipyridinium dication-containing thread-like components sometimes can complicate the synthetic procedures toward such interlocked molecules. A conceptually simpler approach relies upon the crown ether moiety complexing with (mono)pyridinium cations (e.g., the 1-methyl-4-pyrid-4-ylpyridinium cation). If a host macrocycle can recognize a single pyridinium ion to form a [2]pseudorotaxane-like complex ${ }^{10}$ in solution, then the synthesis of a molecular rotaxane from a neutral bipyridine should be quite straightforward: the initial alkylation of one of the pyridine moieties activates the recognition site, which then binds the crown ether, and subsequent alkylation of the second pyridine unit interlocks the two components (Figure 1). ${ }^{11}$

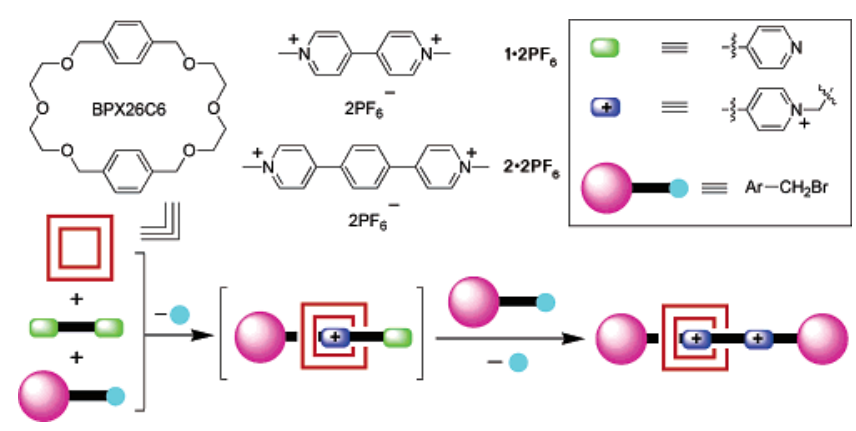

Figure 1.

Although the 1:1 complexation between sizable crown ethers, such as BPP34C10, and bipyridinium dications has been known for almost 2 decades, ${ }^{7 b}$ the recognition of (mono)pyridinium cations by crown ethers remains a challenging task. ${ }^{12}$ In this paper, we report that the crown ether bis-p-xylyl[26]crown-6 (BPX26C6, Figure 1) is capable of binding to the $N, N^{\prime}$-dimethyl-4, $4^{\prime}$-bipyridinium dication to form [3]pseudorotaxane-like complexes both in solution and in the solid state. ${ }^{13}$ This result suggested that BPX26C6 may be able to complex to (mono)pyridinium cations in a [2]-

(8) (a) Jager, R.; Vogtle, F. Angew. Chem., Int. Ed. Engl. 1997, 36, 930. (b) Nepogodiev, S. A.; Stoddart, J. F. Chem. Rev. 1998, 98, 1959. (c) Brouwer, A. M.; Fazio, S. M.; Frochot, C.; Gatti, F. G.; Leigh, D. A.; Wong, J. K. Y.; Wurpel, G. W. H. Pure Appl. Chem. 2003, 75, 1055. (d) Chambron, J.-C.; Collin, J.-P.; Heitz, V.; Jouvenot, D.; Kern, J.-M.; Mobian, P.; Pomeranc, D.; Sauvage, J.-P. Eur. J. Org. Chem. 2004, 1627.

(9) (a) Ashton, P. R.; Philp, D.; Spencer, N.; Stoddart, J. F. J. Chem. Soc., Chem. Commun. 1992, 1124. (b) Vignon, S. A.; Jarrosson, T.; Iijima, T.; Tseng, H.-R.; Sanders, J. K. M.; Stoddart, J. F. J. Am. Chem. Soc. 2004, 126, 9884. (c) Asakawa, M.; Ashton, P. R.; Ballardini, R.; Balzani, V.; Belohradsky, M.; Gandolfi, M. T.; Kocian, O.; Prodi, L.; Raymo, F. M.; Stoddart, J. F.; Venturi, M. J. Am. Chem. Soc. 1997, 119, 302. (d) Belohradsky, M.; Elizarov, A. M.; Stoddart, J. F. Collect. Czech. Chem. Commun. 2002, 67, 1719 .

(10) (a) Asakawa, M.; Ashton, P. R.; Balzani, V.; Boyd, S. E.; Credi, A.; Mattersteig, G.; Menzer, S.; Montalti, M.; Raymo, F. M.; Ruffilli, C.; Stoddart, J. F.; Venturi, M.; Williams, D. J. Eur. J. Org. Chem. 1999, 985. (b) Huang, F.; Zakharov, L. N.; Rheingold, A. L.; Jones, J. W.; Gibson, H. W. Chem. Commun. 2003, 2122.

(11) A similar concept had been applied previously to the construction of molecular rotaxanes; see: Ashton, P. R.; Philp, D.; Spencer, N.; Stoddart, J. F. J. Chem. Soc., Chem. Commun. 1992, 1124.

(12) The first example of the recognition of a (mono)pyridinium ion by a crown ether was reported recently; see: Huang, F.; Slebodnick, C.; Ratliff, A. E.; Gibson, H. W. Tetrahedron Lett. 2005, 46, 6019. pseudorotaxane-like fashion in solution. Taking advantage of the possible crown ether/(mono)pyridinium ion recognition system, we synthesized two [2]rotaxanes in one-pot reactions from nonionic starting materials.

In our continued quest for macrocycles that can recognize different types of guests, ${ }^{14}$ we found that BPX26C6 not only is capable of forming pseudorotaxane-like complexes with dialkylammonium ions but also can recognize $N, N^{\prime}$-dimethyl4,4'-bipyridinium bis(hexafluorophosphate) $\left(\mathbf{1} \cdot 2 \mathrm{PF}_{6}\right)$. We observed significant shifts in the signals in the ${ }^{1} \mathrm{H}$ NMR spectrum $(298 \mathrm{~K})$ of an equimolar $(10 \mathrm{mM})$ mixture of BPX26C6 and $\mathbf{1} \cdot 2 \mathrm{PF}_{6}$ in $\mathrm{CD}_{3} \mathrm{CN}$ (Figure 2). The splitting

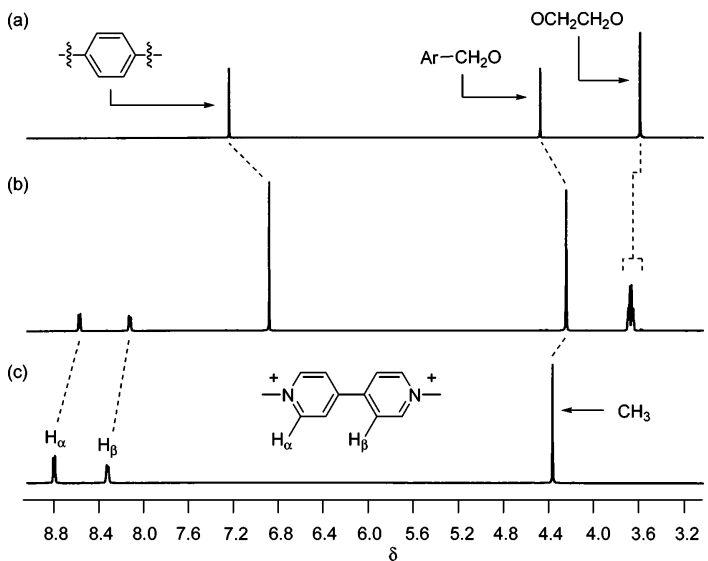

Figure 2. Partial ${ }^{1} \mathrm{H}$ NMR spectra $\left(400 \mathrm{MHz}, \mathrm{CD}_{3} \mathrm{CN}, 298 \mathrm{~K}\right)$ of (a) BPX26C6, (b) an equimolar mixture of BPX26C6 and $1 \cdot 2 \mathrm{PF}_{6}$ $(10 \mathrm{mM})$, and $(\mathrm{c}) \mathbf{1} \cdot 2 \mathrm{PF}_{6}$.

of the originally overlapping signals for the protons of the diethylene glycol unit's two methylene groups in BPX26C6 into a multiplet at $\delta 3.63-3.74$ in the presence of $\mathbf{1}^{2+}$ suggests that $[\mathrm{C}-\mathrm{H} \cdots \mathrm{O}]$ hydrogen bonding probably occurs between the host and guest moieties. The resonances of the xylyl and bipyridinium aromatic protons shifted upfield (to $\delta 6.89,8.14$, and 8.59) from their original positions ( $\delta 7.25$, 8.34 , and 8.79 , respectively); these shifts are characteristic of the existence of aryl-aryl interactions and suggest that the complexation between BPX26C6 and $\mathbf{1}^{2+}$ in solution is likely to have the geometry of a pseudorotaxane.

Using continuous variation methods, ${ }^{15}$ the stoichiometry for the binding between BPX26C6 and $\mathbf{1}^{2+}$ seemed to be 2:1 (Figure 3a). Interestingly, the solid-state structure that we obtained from single crystals of the complex, grown through slow evaporation of a $\mathrm{CH}_{3} \mathrm{CN}$ solution containing a

(13) [3]Pseudorotaxane-like complexes can be generated from dibenzo[24]crown-8 and 2,7-dimethyldiazapyrenium dication; see: Ashton, P. R.; Langford, S. J.; Spencer, N.; Stoddart, J. F.; White, A. J. P.; Williams, D. J. Chem. Commun. 1996, 1387. Cryptand-type hosts and 4,4'-bipyridinium ions also can assemble into [3]pseudorotaxane-like complexes in the solid state, but with 1:1 stoichiometries in solution; see: Huang, F.; Gibson, H. W.; Bryant, W. S.; Nagvekar, D. S.; Fronczek, F. R. J. Am. Chem. Soc. 2003, 125, 9367.

(14) Cheng, P.-N.; Hung, W.-C.; Chiu, S.-H. Tetrahedron Lett. 2005, 46, 4239 .

(15) Connors, K. A. Binding Constants; Wiley: New York, 1987. 

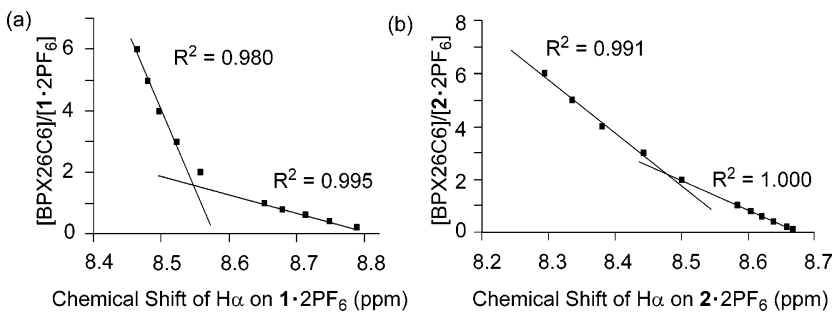

Figure 3. Molar ratio plots $\left(\mathrm{CD}_{3} \mathrm{CN}\right)$ for (a) BPX26C6 and 1. $2 \mathrm{PF}_{6}$ and (b) BPX26C6 and $2 \cdot 2 \mathrm{PF}_{6}$.

1:1 mixture of BPX26C6 and $\mathbf{1} \cdot 2 \mathrm{PF}_{6}$, reveals a [3]pseudorotaxane-like geometry, $\left[(\mathrm{BPX} 26 \mathrm{C} 6)_{2} \supset \mathbf{1}\right] \cdot 2 \mathrm{PF}_{6}$ (Figure 4).

(a)

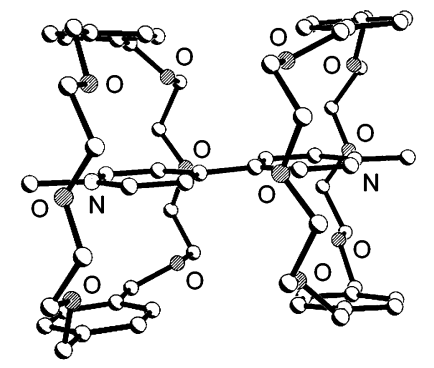

(b)

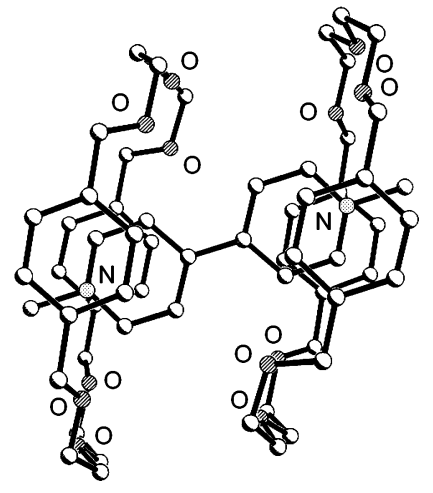

Figure 4. Ball-and-stick representations of the solid-state structure of the [3]pseudorotaxane-like complex [(BPX26C6 $\left.)_{2} \supset 1\right]^{2+}$ : (a) side view; (b) top view.

The electrospray ionization (ESI) mass spectrum recorded from an equimolar mixture of $\mathbf{1} \cdot 2 \mathrm{PF}_{6}$ and BPX26C6 reveals peaks at $m / z, 1163$ and 747, which correspond to 2:1 and 1:1 complexes, respectively, that have each lost one $\mathrm{PF}_{6}{ }^{-}$ion.

Having determined that BPX26C6 and $\mathbf{1} \cdot 2 \mathrm{PF}_{6}$ can form stable [3]pseudorotaxane-like complexes in solution, in the gas phase, and in the solid state, we turned our attention toward the estimation of the association constants $\left(K_{1}\right.$ and $K_{2}$ ) to determine whether cooperativity exists between the first and second binding events. Figure 5a displays the nonlinear Scatchard plot that we obtained for the binding of BPX26C6 and $1 \cdot 2 \mathrm{PF}_{6}$ after determining the extent of complexation $(p)$ of the bipyridinium units from the ${ }^{1} \mathrm{H}$ NMR data for proton $\mathrm{H}_{\alpha}$ of $\mathbf{1} \cdot 2 \mathrm{PF}_{6} .{ }^{16}$ From this Scatchard plot,

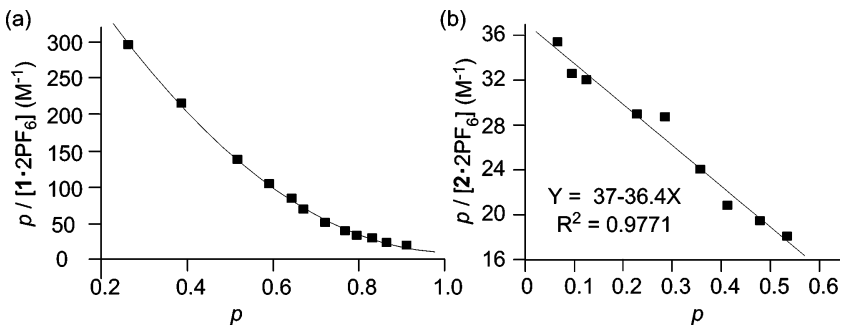

Figure 5. Scatchard plots $\left(\mathrm{CD}_{3} \mathrm{CN}, 298 \mathrm{~K}\right)$ for the complexation of BPX26C6 with (a) $\mathbf{1} \cdot 2 \mathrm{PF}_{6}\left(\left[\mathbf{1} \cdot 2 \mathrm{PF}_{6}\right]_{0}=0.5 \mathrm{mM}\right)$ and (b) $\mathbf{2} \cdot$ $2 \mathrm{PF}_{6}\left(\left[2 \cdot 2 \mathrm{PF}_{6}\right]_{0}=0.5 \mathrm{mM}\right) ; p$ defines the fraction of bound guest. The second-order polynomial fitting line in (a) is presented merely to guide the eye.

we estimated $K_{1}$ and $K_{2}$ to be $700 \pm 80$ and $60 \pm 25 \mathrm{M}^{-1}$, respectively. ${ }^{17}$ The ratio of $K_{2}$ to $K_{1}$ is 0.086 ; this value is significantly lower than the value $(0.25)$ expected $^{18}$ for statistical complexation and suggests negative cooperativity ${ }^{19}$ during the binding of the second crown ether unit, presumably because of steric factors. To test this hypothesis, we synthesized 1,4-bis(1-methylpyridinium)phenylene bis(hexafluorophosphate) $2 \cdot 2 \mathrm{PF}_{6}$, an analogue of $1 \cdot 2 \mathrm{PF}_{6}$ in which the two $N$-methylpyridinium units are separated via a $p$-phenylene unit, and dissolved it in $\mathrm{CD}_{3} \mathrm{CN}$ in the presence of an equimolar (10 mM) amount of BPX26C6. We observed shifts in the signals in the ${ }^{1} \mathrm{H}$ NMR spectrum of this mixture (see Supporting Information) that are similar to those of the $\mathrm{BPX} 26 \mathrm{C} 6 / 1 \cdot 2 \mathrm{PF}_{6}$ system. We determined, using the molar ratio method, that a $2: 1$ binding stoichiometry also exists between BPX26C6 and $\mathbf{2} \cdot 2 \mathrm{PF}_{6}$ (Figure $3 \mathrm{~b}$ ). The Scatchard plot of the complexation is linear (Figure 5b), which suggests independent (i.e., noncooperative) binding of the two $N$ methylpyridinium ions in $\mathbf{2} \cdot 2 \mathrm{PF}_{6}$ by the BPX26C6 units. We determined the association constants $K_{1}$ and $K_{2}(72 \pm 8$ and $18 \pm 2 \mathrm{M}^{-1}$, respectively) from the slope of this line. ${ }^{20}$ Interestingly, the association constant for the first binding

(16) We used the Benesi-Hildebrand method (ref 15), based on a series of ${ }^{1} \mathrm{H}$ NMR spectroscopy experiments with constant $\left[\mathbf{1} \cdot 2 \mathrm{PF}_{6}\right]$ or $\left[\mathbf{2} \cdot 2 \mathrm{PF}_{6}\right]$ and various values of [BPX26C6], to determine the differences in $\delta$ values ( $\Delta_{0}$ for the $\alpha$-proton of the uncomplexed and fully complexed $\mathbf{1} \cdot 2 \mathrm{PF}_{6}$. Thus, $p=\Delta / \Delta_{0}$, where $\Delta$ is the chemical shift change relative to that of the free species (see ref $6 \mathrm{a})$. We fitted the values of $\Delta$ using a nonlinear leastsquares method (WinEQNMR) to obtain the values of $K_{1}$ and $K_{2}(990 \pm$ 240 and $32 \pm 10 \mathrm{M}^{-1}$, respectively). For WinEQNMR software, see: Hynes, M. J. J. Chem. Soc., Dalton Trans. 1993, 311.

(17) The slope of the first four data points for low values of $p$ gave the value of $2 K_{2}-K_{1}$. The slope of the last four data points (high values of $p$ ) gave the value of $-2 K_{2}$. See: Perlmutter-Hayman, B. Acc. Chem. Res. 1986, 19, 90. We calculated the errors of the association constants on the basis of the error of the slope.

(18) In a system possessing two identical binding sites for its complementary partner, with association constants $K_{1}$ and $K_{2}$, respectively, $K_{1}=$ $4 K_{2}$ if the binding sites operate independently. A system is positively cooperative if $K_{2} / K_{1}$ is greater than 0.25 and negatively cooperative if $K_{2}$ $K_{1}$ is smaller than 0.25; see: (a) Chang, T.; Heiss, A. M.; Cantrill, S. J.; Fyfe, M. C. T.; Pease, A. R.; Rowan, S. J.; Stoddart, J. F.; Williams, D. J. Org. Lett. 2000, 2, 2943. (b) Reference 15. (c) Reference 17.

(19) The linearity of the data points in the Scatchard plot also provides information regarding the cooperativity; see: Gibson, H. W.; Yamaguchi, N.; Hamilton, L.; Jones, J. W. J. Am. Chem. Soc. 2002, 124, 4653.

(20) The value of the slope is -36 , which equals the values of both $-2 K_{2}$ and $2 K_{2}-K_{1}$ simultaneously. We calculated the errors of the association constants on the basis of the error of the slope. 
event $\left(K_{1}\right)$ during the complexation of $1 \cdot 2 \mathrm{PF}_{6}$ with BPX26C6 is ca. 10 times higher than that of $2 \cdot 2 \mathrm{PF}_{6}$, presumably because increased delocalization of positive charges in the extended $\pi$ system of $\mathbf{2}^{2+}$.

The fact that BPX26C6 binds to $2 \cdot 2 \mathrm{PF}_{6}$ in $2: 1$ stoichiometry suggests that it may also recognize (mono)pyridinium ions in [2]pseudorotaxane-like geometries in solution. If so, it would open up the possibility of using such systems for the facile syntheses of [2]rotaxanes. We suspected that BPX26C6, 3,5-di-tert-butylbenzyl bromide, and 4,4'-dipyridyl could undergo two-step reactions in one pot to generate the corresponding [2]rotaxanes: (1) N-alkylation of dipyridyl with the benzyl bromide to generate a monoalkyl pyridinium ion, which is then encircled by a BPX26C6 unit to form the corresponding [2] semirotaxane, ${ }^{21}$ followed by (2) a second $\mathrm{N}$-alkylation of the remaining pyridine unit of the thread component with another equivalent of the benzyl bromide; this second reaction would interlock the BPX26C6 moiety along the rodlike unit of the dumbbell-shaped component of the [2]rotaxane. Gratifyingly, we used this approach for the successful syntheses of the [2] rotaxanes $\mathbf{5} \cdot 2 \mathrm{PF}_{6}$ (isolated yield $70 \%$ ) and $\mathbf{6} \cdot 2 \mathrm{PF}_{6}(25 \%)^{22}$ (Scheme 1) from the

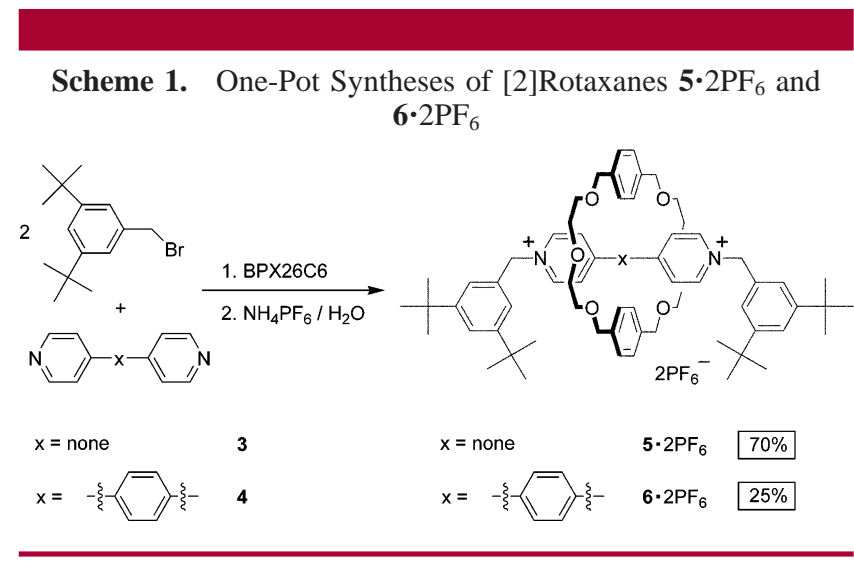

reactions of BPX26C6, 3,5-di-tert-butylbenzyl bromide, and the bipyridines 3 and $\mathbf{4}$, respectively, in $\mathrm{CH}_{3} \mathrm{CN}$. We used vapor diffusion of isopropyl ether into a $\mathrm{CH}_{3} \mathrm{CN}$ solution of $\mathbf{5} \cdot 2 \mathrm{PF}_{6}$ to obtain single crystals that were suitable for X-ray crystallographic analysis, and the solid-state structure (Figure 6) reveals the expected [2]rotaxane.

The syntheses of these [2] rotaxanes prove unambiguously that [2]pseudorotaxane-like complexes can exist between

(21) A semirotaxane has been defined as a pseudorotaxane possessing a stoppering unit at one terminus of the rodlike component. See: (a) Collin, J.-P.; Gaviña, P.; Sauvage, J.-P. New J. Chem. 1997, 21, 525. (b) Seel, C.; Parham, A. H.; Safarowsky, O.; Hübner, G. M.; Vögtle, F. J. Org. Chem. 1999, 64, 7236.

(22) At the reaction concentration $(240 \mathrm{mM}), 4,4^{\prime}$-dipyridyl (3) was completely soluble in $\mathrm{MeCN}$, but the bipyridine 4 was not; thus, the relatively lower yield of the [2] rotaxane $\mathbf{6} \cdot 2 \mathrm{PF}_{6}$ may arise either from the low reaction concentration of the (mono)pyridinium intermediate from 4 or from its weaker association with BPX26C6.

(23) In addition to the small values of $K_{2}$ for the binding of BPX26C6 to $\mathbf{1} \cdot 2 \mathrm{PF}_{6}$ and $\mathbf{2} \cdot 2 \mathrm{PF}_{6}$, we determined that complex formation between BPX26C6 and $N$-methyl-4-methylpyridinium hexafluorophosphate in $\mathrm{CD}_{3}$ $\mathrm{CN}$ at $25^{\circ} \mathrm{C}$ occurred with a binding constant of $16 \pm 2 \mathrm{M}^{-1}$.

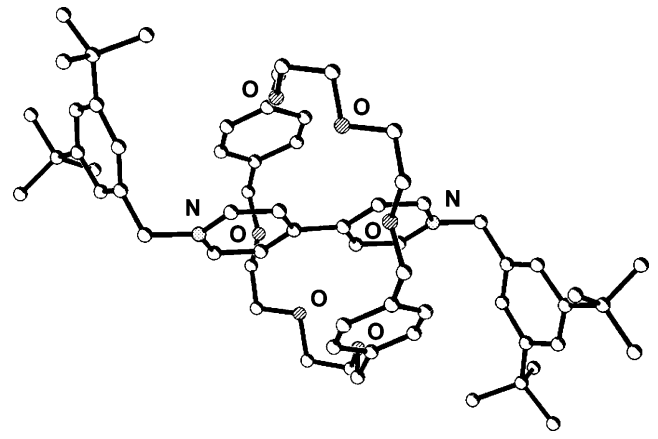

Figure 6. Ball-and-stick representation of the solid-state structure of the [2] rotaxane $\mathbf{5} \cdot 2 \mathrm{PF}_{6}$.

BPX26C6 and (mono)pyridinium ions in solution. Because (mono)pyridinium recognition sites for BPX26C6 can be established in situ, one-pot [2]rotaxane syntheses can be performed from readily available reagents without the need to use ionic starting materials possessing preinstalled recognition sites. Even though association constants for the interactions of BPX26C6 with (mono)pyridinium ions are small, ${ }^{23}$ the yields of the [2] rotaxanes were surprisingly high. This result suggests that a relatively high concentration of (mono)pyridinium ions is generated in solution to facilitate the formation of the corresponding [2] semirotaxanes with BPX26C6. The weaker nucleophilicity of the nitrogen atom in the more electron-deficient (mono)pyridinium ion, relative to those in the neutral bipyridyls, may be responsible for the production of substantial amount of (mono)pyridinium ion in solution. It is also possible that the encircling crown ether donates some of its electron density (i.e., through charge transfer) to the thread component of the [2]semirotaxane to enhance the nucleophilicity of the nitrogen atom of the remaining pyridine unit, which facilitates the production of the [2] rotaxane rather than the dumbbell-shaped bipyridinium salt.

BPX26C6 is capable of forming [2]pseudorotaxane-like complexes with (mono)pyridinium ions; this property results in BPX26C6 forming [3]pseudorotaxane complexes with bipyridinium ions both in solution and in the solid state. This unique recognition behavior allows [2] rotaxanes to be prepared in one-pot reactions of BPX26C6, bipyridine derivatives, and moderately bulky benzyl bromides.

Acknowledgment. We thank the National Science Council (Taiwan) for financial support (NSC-94-2113-M-002011).

Supporting Information Available: Synthetic procedures and characterization data for BPX26C6, 5.2PF , and $\mathbf{6} \cdot 2 \mathrm{PF}_{6}$, including CIF files. This material is available free of charge via the Internet at http://pubs.acs.org.

OL052679N 